Article

\title{
The Fabrication and Characterization of InAlAs/InGaAs APDs Based on a Mesa-Structure with Polyimide Passivation
}

\author{
Jheng-Jie Liu ${ }^{1}$, Wen-Jeng Ho ${ }^{1} * \mathbb{E}$, June-Yan Chen ${ }^{1}$, Jian-Nan Lin ${ }^{1}$, Chi-Jen Teng ${ }^{2}$, \\ Chia-Chun $\mathrm{Yu}^{2}$, Yen-Chu $\mathrm{Li}^{2}$ and Ming-Jui Chang ${ }^{2}$ \\ 1 Department of Electro-Optical Engineering, National Taipei University of Technology, No. 1, Section 3, \\ Zhongxial East Road, Taipei 10608, Taiwan \\ 2 Tyntek Corp., No. 15, Kejung Rd., Chunan Science Park, Chunan, Miaoli County 350, Taiwan \\ * Correspondence: wjho@ntut.edu.tw; Tel.: +886-2-2771-2171 (ext. 4639)
}

Received: 14 June 2019; Accepted: 31 July 2019; Published: 2 August 2019

check for updates

\begin{abstract}
This paper presents a novel front-illuminated InAlAs/InGaAs separate absorption, grading, field-control and multiplication (SAGFM) avalanche photodiodes (APDs) with a mesa-structure for high speed response. The electric fields in the InAlAs-multiplication layer and InGaAs-absorption layer enable high multiplication gain and high-speed response thanks to the thickness and concentration of the field-control and multiplication layers. A mesa active region of 45 micrometers was defined using a bromine-based isotropic wet etching solution. The side walls of the mesa were subjected to sulfur treatment before being coated with a thick polyimide layer to reduce current leakage, while lowering capacitance and increasing response speeds. The breakdown voltage $\left(\mathrm{V}_{\mathrm{BR}}\right)$ of the proposed SAGFM APDs was approximately $32 \mathrm{~V}$. Under reverse bias of $0.9 \mathrm{~V}_{\mathrm{BR}}$ at room temperature, the proposed device achieved dark current of $31.4 \mathrm{nA}$, capacitance of $0.19 \mathrm{pF}$ and multiplication gain of 9.8. The 3-dB frequency response was $8.97 \mathrm{GHz}$ and the gain-bandwidth product was $88 \mathrm{GHz}$. A rise time of $42.0 \mathrm{ps}$ was derived from eye-diagrams at $0.9 \mathrm{~V}_{\mathrm{BR}}$. There was notable absence of intersymbol-interference and the signals remained error-free at data-rates of up to $12.5 \mathrm{Gbps}$.
\end{abstract}

Keywords: avalanche photodiodes; InAlAs; InP; multiplication gain; polyamide passivation; eye-diagrams

\section{Introduction}

Avalanche photodiodes (APDs) featuring a separate absorption and multiplication (SAM) layer-structure are widely used to produce low-noise optical detectors of high sensitivity $[1,2]$. InGaAs/InP APDs comprise an absorption layer of $\mathrm{In}_{0.53} \mathrm{Ga}_{0.47} \mathrm{As}$ (hereafter referred to as InGaAs) with a multiplication layer of InP. These devices have long been used as high-performance detectors in optical communication systems operating at wavelengths of 1310 or $1550 \mathrm{~nm}$ [3-5]. However, $\mathrm{In}_{0.52} \mathrm{Al}_{0.48} \mathrm{As}$ (hereafter referred to as InAlAs) is attracting considerable attention for use in the multiplication layer for three main reasons: (1) The electron/hole ionization coefficient of InAlAs is larger than that of InP [6-9]; (2) The electron mobility of InAlAs is greater than that of InP [10,11]; and (3) The ionization coefficient of InGaAs/InAlAs APDs is less sensitive than InGaAs/InP APDs to variations in temperature [6-9,12-15]. As a result, InGaAs/InAlAs APDs achieve far higher performance in terms of noise, gain-bandwidth, response time and resistance to temperature variation $[14,16,17]$. 
In this study, we fabricated front-side illuminated mesa-type InGaAs/InAlAs APDs based on a separate absorption, grading, field-control and multiplication (SAGFM) layer structure in conjunction with multi-step mesa etching and sulfur/polyimide passivation to achieve high-speed operations and high sensitivity [18-22]. Electric-field distribution in the multiplication and absorption layers is well controlled to enable high multiplication gain and low noise. The proposed device was evaluated in terms of dark current, breakdown voltage, multiplication gain, capacitance, incident optical power dynamic range, aging test, frequency response and transmission speeds at room temperature.

\section{Experiments}

\subsection{Epitaxial Layer Design and the Calculation of Electric-Field Profiles}

The proposed avalanche photodiode (APD) was configured using separate absorption, grading, field-control and multiplication (SAGFM) layer-structure. Table 1 details the parameters of the epitaxial layers, which were grown using molecular beam epitaxy (MBE) on semi-insulated InP wafers with (100) orientation and low etch pit density (EPD), measuring two inches in diameter and $350 \mu \mathrm{m}$ in thickness. The quality of the epitaxial layers was verified via double-crystal X-ray diffraction (to check for lattice mismatch between hetero-junction layers less than $300 \mathrm{ppm}$ ), photoluminescence (to assess the optical properties of InGaAlAs, InAlAs, InGaAs and InP layers) and electrochemical capacitance-voltage (to measure the carrier concentrations of $\mathrm{P}^{+}$-InGaAs contact-layer, $\mathrm{p}$-InP window-layer, i-InGaAs absorber, $\mathrm{p}$-InAlAs field control-layer and $\mathrm{n}^{+}$-InAlAs contact-layer). Scanning electron microscopy (SEM) was used to measure the thickness of the epitaxial layers and characterize the interface between layers. Note that the doping concentration and thickness of the field control layer were factors of critical importance. All measurements pertaining to the epitaxial layers were confirmed by the semiconductor foundry (Intelligent Epitaxy Technology Inc., Richardson, TX, USA).

The electric field profiles of the multiplication and absorption layers were controlled by adjusting the doping and thickness of the p-InAlAs field-control layer, InAlAs multiplication layer and the InGaAs absorption layer. The electric field distribution was calculated using simulation software in accordance with the proposed layer parameters. The proposed SAGFM APD was fabricated using an un-doped InAlAs multiplication layer (0.3- $\mu \mathrm{m}$-thick), an un-doped InGaAs absorption layer (1.2- $\mu \mathrm{m}$-thick) and a p-InAlAs field-control layer (0.2- $\mu \mathrm{m}$-thick) to enable high-speed operations.

Table 1. Details of epitaxial layers in SAGFM APD.

\begin{tabular}{cccc}
\hline Layer Name & Epitaxial Layer & Thickness $(\mu \mathrm{m})$ & Concentration $\left(\mathbf{c m}^{-\mathbf{3}}\right)$ \\
\hline Contact & $\mathrm{P}^{+}$-InGaAs & 0.1 & $1.0-3.0 \times 10^{19}$ \\
Window & p-InP & 0.35 & $5.0-6.0 \times 10^{18}$ \\
Grading & i-InGaAlAs & 0.03 & Undoped \\
Absorber & i-InGaAs & 1.2 & Undoped \\
Grading & i-InGaAlAs & 0.03 & Undoped \\
Field control & p-InAlAs & 0.2 & $2.0 \times 10^{17}$ \\
Multiplication & i-InAlAs & 0.3 & Undoped \\
Contact & $\mathrm{n}^{+}-$InAlAs & 1.0 & $5.0-6.0 \times 10^{18}$ \\
Buffer & n-InP & 0.5 & $1.0-5.0 \times 10^{17}$ \\
Semi-insulating & - & 350 & - \\
\hline
\end{tabular}




\subsection{Fabrication and Characterization of InAlAs/InGaAs APDs}

Epitaxial wafers were cut into samples measuring $1 \times 1 \mathrm{~cm}^{2}$ for the fabrication of SAGFM APD devices. After standard cleaning, a 5- $\mu \mathrm{m}$-wide $\mathrm{p}^{+}$-InGaAs circular contact-ring (30- $\mu$ m diameter) was created on the front surfaces of the samples through the selective etching of InGaAs from InP using a solution of $\mathrm{H}_{3} \mathrm{PO}_{4}: \mathrm{H}_{2} \mathrm{O}_{2}: \mathrm{H}_{2} \mathrm{O}(1: 1: 38)$. Ti/Pt/Au $(10 \mathrm{~nm} / 20 \mathrm{~nm} / 300 \mathrm{~nm})$ films were then deposited on the $\mathrm{p}^{+}$-InGaAs contact-ring via E-beam evaporation and photolithographic lift-off processing. The samples were then subjected to annealing in a rapid thermal annealing (RTA) chamber at $420^{\circ} \mathrm{C}$ for $1 \mathrm{~min}$ to ensure the formation of a good p-ohmic contact [23]. Bromine-based isotropic wet etching solution $\left(\mathrm{H}_{3} \mathrm{PO}_{4}: \mathrm{HBr}: \mathrm{K}_{2} \mathrm{Cr}_{2} \mathrm{O}_{3} ; 1: 1: 1\right)$ was used to define a primary circular mesa active region (40- $\mu \mathrm{m}$ diameter) as far as the $\mathrm{n}^{+}$-InAlAs contact layer as well as a secondary circular mesa active region (45- $\mu \mathrm{m}$ diameter) as far as the semi-insulating InP substrate to ensure device isolation [24]. The etched sample was then immersed in hot $\mathrm{H}_{2} \mathrm{SO}_{4}$ solution $\left(60{ }^{\circ} \mathrm{C}\right)$ for $60 \mathrm{~s}$ followed by $\mathrm{HF}: \mathrm{H}_{2} \mathrm{O}(1: 5)$ treatment for $60 \mathrm{~s}$ in order to remove native oxides from the smooth mesa surface. Sulfur passivation was performed immediately after, by immersing the samples in $\left(\mathrm{NH}_{4}\right)_{2} \mathrm{~S}_{\mathrm{x}}$ solution for $40-60 \mathrm{~min}$ in a constant temperature bath [25-27]. Photosensitive polyimide (CRC 8000 Series Product, Sumitomo Bakelite Co., Ltd.; Tokyo, Japan) was applied via spin-on coating and patterned for use as a capping layer over the sulfur passivated surface [28]. The polyimide was cured by ramping up the temperature $\left(5{ }^{\circ} \mathrm{C}\right.$ per min) until it reached $350{ }^{\circ} \mathrm{C}$, where it was held for $30 \mathrm{~min}$ before being ramped down $\left(5^{\circ} \mathrm{C}\right.$ per min) to room temperature. The entire curing process was performed under ambient $\mathrm{N}_{2}$. After curing, the thickness of the polyimide was approximately $4.0 \mu \mathrm{m}$. Polyimide within the region of the $\mathrm{n}^{+}$-InAlAs contact-ring was removed for n-electrode metallization. A N-ohmic contact was created by evaporating AuGeNi/Au (50 nm/500 nm) films followed by annealing in an RTA chamber at $350{ }^{\circ} \mathrm{C}$ for $30 \mathrm{~s}$ under ambient $\mathrm{N}_{2}$ to ensure a good ohmic contact. Note that a smooth mesa is essential for good surface passivation effects. Finally, SiNx was deposited to a thickness of $180 \mathrm{~nm}$ on the front surface of the APD as an antireflective coating. Figure 1a presents a schematic illustration of the proposed SAGFM APD. Figure $1 b$ presents a top-view schematic diagram of the test pads on APD chips for the microwave probe used to characterize the frequency and time response. Note that the metal bond pads (Ti/Pt/Au; $20 \mathrm{~nm} / 30 \mathrm{~nm} / 1000 \mathrm{~nm}$ ) were connected to the $\mathrm{p}$ - and n-electrodes. We sought to minimize the length of connection metallization in order to reduce the inductance component and thereby achieve high-frequency response. The performance of the fabricated APD was characterized in terms of dark current-voltage (I-V), capacitance-voltage (C-V), photo I-V, multiplication gain (M), time and frequency response.

(a)

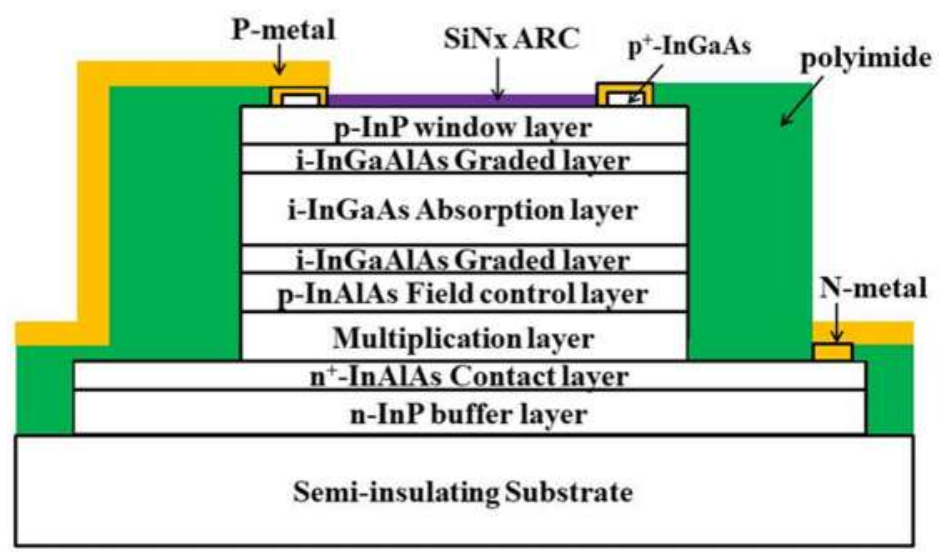

(b)

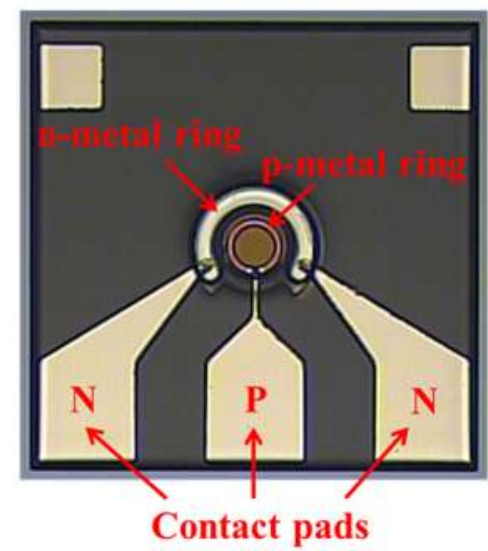

Figure 1. Schematic diagram showing InAlAs/InGaAs separate absorption, grading, field-control and multiplication (SAGFM) avalanche photodiode: (a) Side-view, (b) top-view. 


\subsection{Electric Field Profile Calculation}

In this study, the InAlAs/InGaAs APD, light absorption and carrier multiplication processes were kept separate by employing an InGaAs absorption layer with a small band gap $\left(\mathrm{E}_{\mathrm{g}}=0.75 \mathrm{eV}\right)$ and a InAlAs multiplication layer with a large band gap $\left(\mathrm{E}_{\mathrm{g}}=1.46 \mathrm{eV}\right)$. Two InGaAlAs graded layers were used to shift the band gap from $0.75 \mathrm{eV}$ (InGaAs) to $1.35 \mathrm{eV}$ (InP) and from $0.75 \mathrm{eV}$ (InGaAs) to $1.46 \mathrm{eV}$ (InAlAs) to assist in the transport of carriers (generated in the absorption layer) into the multiplication and window layers. The function of the $\mathrm{p}$-InAlAs field control layer was to maintain a high electric field for the multiplication layer and a low electric field for the absorption layer in order to prevent high-field induced current tunneling. The InAlAs multiplication layer requires an electric field intensity of $>5 \times 10^{5} \mathrm{~V} / \mathrm{cm}$ to achieve carrier multiplication via impact ionization and $>2 \times 10^{4} \mathrm{~V} / \mathrm{cm}$ to rapidly sweep out the carriers generated in the InGaAs absorption layer (i.e., prior to recombination). This requires the optimization of electric field distribution in the absorption and multiplication layers. Typically, a SAGFM APD structure would require an electric field distribution of $5 \times 10^{5}-8 \times 10^{5} \mathrm{~V} / \mathrm{cm}$ in the InAlAs multiplication layer and $2 \times 10^{4}-2 \times 10^{5} \mathrm{~V} / \mathrm{cm}$ in the InGaAs absorption layer. Figure 2 presents the electric field profile, the calculation of which was based on the parameters of the epitaxial layer in the SAGFM APD (see Table 1), as a function of the distance from the p-n junction under various reverse bias voltages. Our results indicate that the electric field intensity profile was well controlled to the range required for the InAlAs multiplication layer $\left(5 \times 10^{5}-8 \times 10^{5} \mathrm{~V} / \mathrm{cm}\right)$ and the InGaAs absorption layer $\left(2 \times 10^{4}-2 \times 10^{5} \mathrm{~V} / \mathrm{cm}\right)$ when the APD was operated at a voltage of $0.9 \mathrm{~V}_{\mathrm{BR}}$.

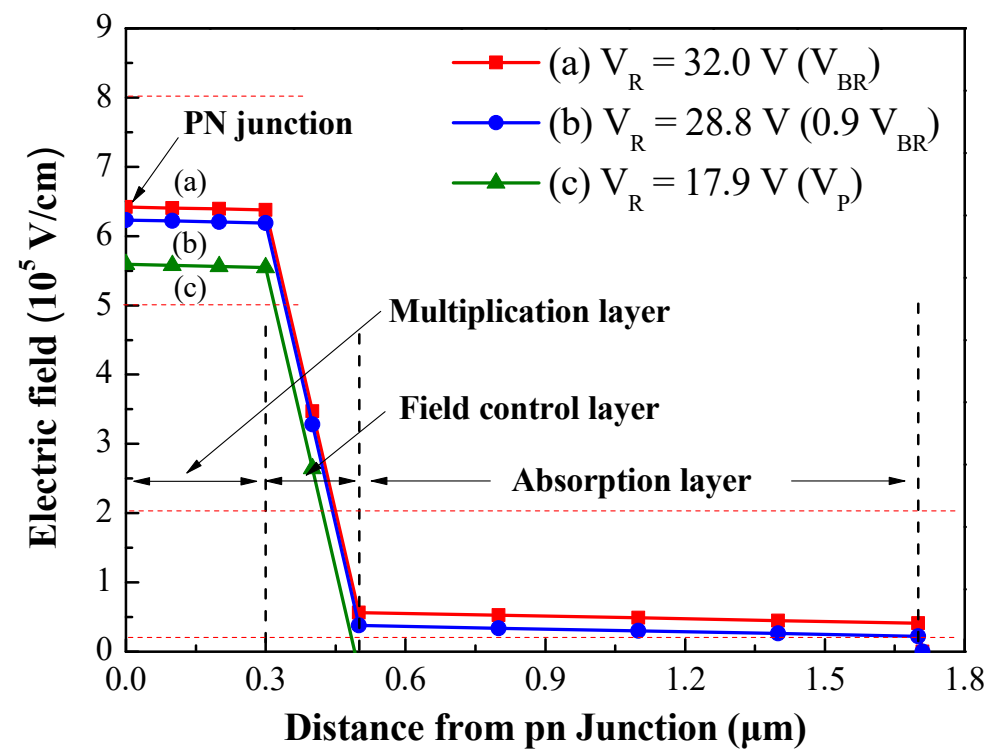

Figure 2. Electric field profile, calculated as a function of the distance from the p-n junction under various reverse bias voltages.

\section{Results and Discussion}

\subsection{Characteristics of SAGFM APD}

Figure 3 presents dark forward I-V curves obtained from the proposed SAGFM APD before and after passivation/polyimide coating. The ideality factor $(\mathrm{n})$ and reverse saturation current $\left(\mathrm{J}_{0}\right)$ of the InGaAs/InAlAs SAGFM APD (as extracted from dark I-V curves) were as follows: Before passivation/coating $\left(\mathrm{n}=2.79\right.$ and $\left.\mathrm{J}_{0}=3.21 \times 10^{-7} \mathrm{~A} / \mathrm{cm}^{2}\right)$ and after passivation/coating $(\mathrm{n}=1.86$ and $\left.\mathrm{J}_{0}=3.55 \times 10^{-9} \mathrm{~A} / \mathrm{cm}^{2}\right)$. The reduction in $\mathrm{n}$ and $\mathrm{J}_{0}$ values after passivation are indications of suppressed surface recombination and current leakage. The series resistance $\left(R_{S}\right)$ and shunt resistance $\left(R_{S H}\right)$ of the SAGFM APD were as follows: Before passivation/coating $\left(R_{\mathrm{S}}=11.94 \Omega\right.$ and $\left.\mathrm{R}_{\mathrm{SH}}=29.7 \mathrm{M} \Omega\right)$ and after passivation/coating $\left(R_{\mathrm{S}}=10.11 \Omega\right.$ and $\left.\mathrm{R}_{\mathrm{SH}}=34.3 \mathrm{M} \Omega\right)$. The increase in $\mathrm{R}_{\mathrm{SH}}$ demonstrates the 
effectiveness of sulfur and polyimide passivation when applied to a mesa-structure SAGFM APD. All diode parameters of the SAGFM APD are listed in Table 2.

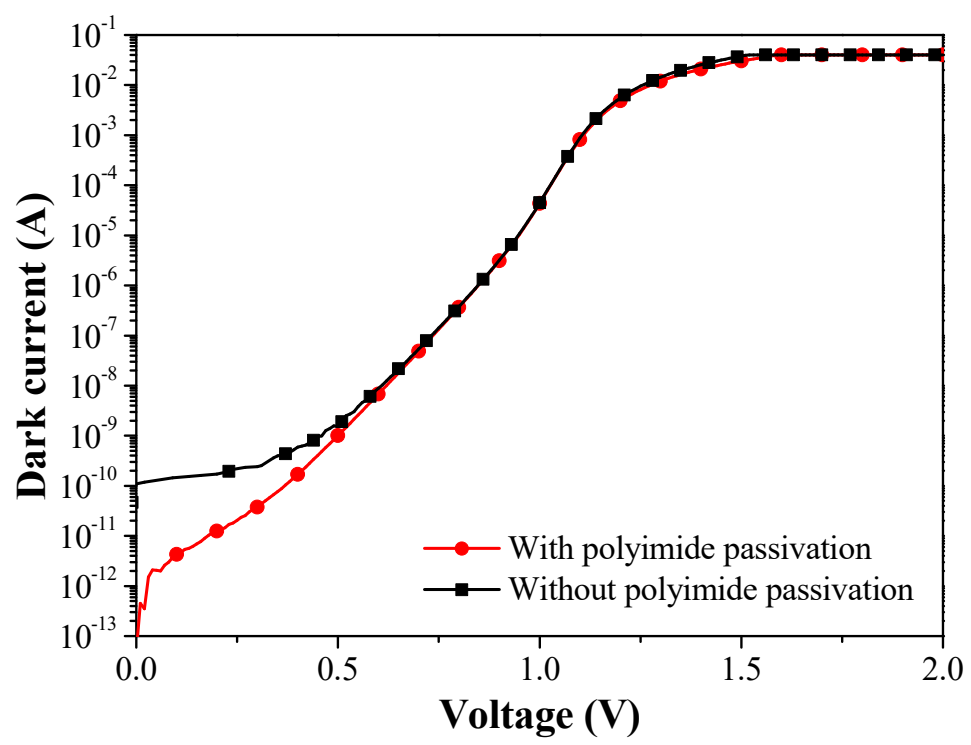

Figure 3. Dark I-V curves of SAGFM avalanche photodiodes (APD) before and after passivation/polyimide coating.

Table 2. Diode performance parameters of SAGFM APD.

\begin{tabular}{ccccc}
\hline Parameter & Symbol & With Polyimide & Without Polyimide & Unit \\
\hline Series resistance & Rs & 10.11 & 11.94 & $\Omega$ \\
Shunt resistance & Rsh & 34.3 & 29.7 & $\mathrm{M} \Omega$ \\
Ideality factor & $\mathrm{n}$ & 1.86 & 2.79 & - \\
Reverse Saturation Current Density & $\mathrm{J}_{0}$ & $3.55 \times 10^{-9}$ & $3.21 \times 10^{-7}$ & $\mathrm{~A} / \mathrm{cm}^{2}$ \\
\hline
\end{tabular}

Figure 4 presents the dark current $\left(I_{D}\right)$, capacitance $(\mathrm{C})$, photocurrent $\left(I_{p h}\right)$ and multiplication gain $(\mathrm{M})$ as a function of reverse bias voltage. Photocurrent measurements were obtained under illumination using a light source with wavelength of $1550 \mathrm{~nm}$ and optical power of $1 \mu \mathrm{W}$. The punch through voltage and the breakdown voltage of SAGFM APD were respectively $17.9 \mathrm{~V}$ and $32.0 \mathrm{~V}\left(I_{D}\right.$ of $10 \mu \mathrm{A}$ ), as measured at room temperature. At $0.9 \mathrm{~V}_{\mathrm{BR}}$, the dark current was $31.4 \mathrm{nA}$, the capacitance was $0.19 \mathrm{pF}$ and the multiplication gain was 9.8. At a temperature of $300 \mathrm{~K}$ under $1 \mu \mathrm{W}$ illumination, the responsivity and a multiplication gain were as follows: $0.9 \mathrm{~V}_{\mathrm{BR}}(8.04 \mathrm{~A} / \mathrm{W}$ and 9.8$)$ and $0.95 \mathrm{~V}_{\mathrm{BR}}$ (18.94 $\mathrm{A} / \mathrm{W}$ and 23.1). The maximum multiplication gain at $\mathrm{V}_{\mathrm{BR}}$ was 994 . The low dark current, low capacitance and high multiplication gain of the InGaAs/InAlAs SAGFM APD demonstrate the applicability of the proposed device for high-speed optical communication systems. For the sake of clarity, we calculated the multiplication gain (M) of the APD as follows:

$$
M=\frac{I_{p h}-I_{D}}{I_{p h o}-I_{D o}}
$$

where $I_{p h}$ is the APD photocurrent that has been multiplied, $I_{p h o}$ is the unmultiplied photocurrent, $I_{D}$ is the APD dark current that has been multiplied and $I_{D o}$ is the unmultiplied dark current. 


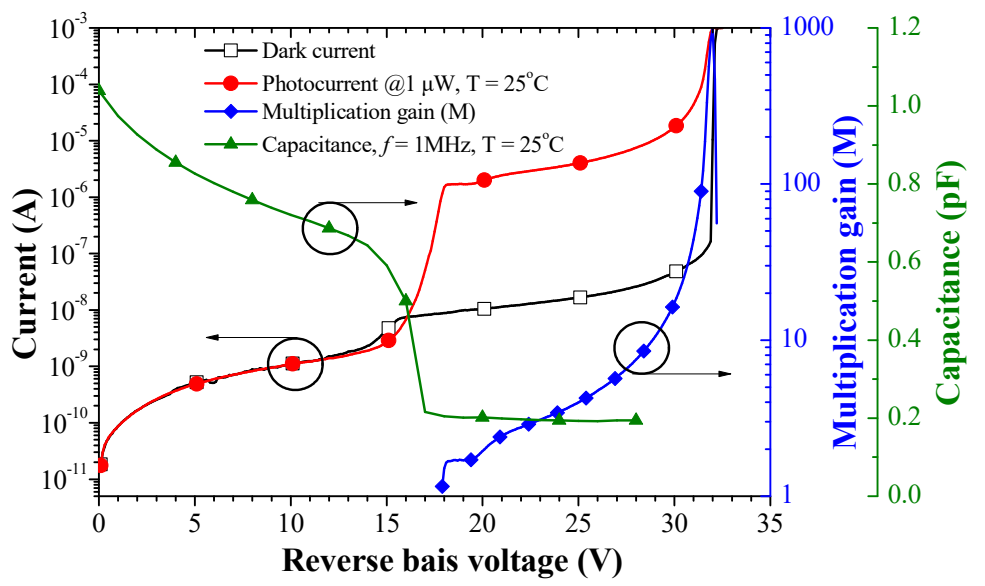

Figure 4. Dark current, capacitance, photocurrent and multiplication factor of InGaAs/InAlAs SAGFM $\mathrm{APD}$ as a function of reverse bias voltage.

Figure 5 presents the breakdown voltage of InP-based [29] and InAlAs-based APDs (current work) as a function of operating temperature. Generally, the bias of an APD is controlled with the aim of preserving the gain of the device despite fluctuations in temperature. However, most APD devices used in optical fiber communication systems are meant to be operated at temperatures between $-40{ }^{\circ} \mathrm{C}$ and $85^{\circ} \mathrm{C}$. Thus, the knowledge of how avalanche breakdown voltage changes with temperature could be useful. As shown in Figure 5, the breakdown voltage temperature coefficient $\left(\Delta V_{B R} / \Delta T\right)$ of InP-based and InAlAs-based APDs were $0.105 \mathrm{~V} /{ }^{\circ} \mathrm{C}[29]$ and $0.028 \mathrm{~V} /{ }^{\circ} \mathrm{C}$, respectively. These results demonstrate that the InAlAs-based APD was less sensitive than the InP-based APD to variations in temperature.

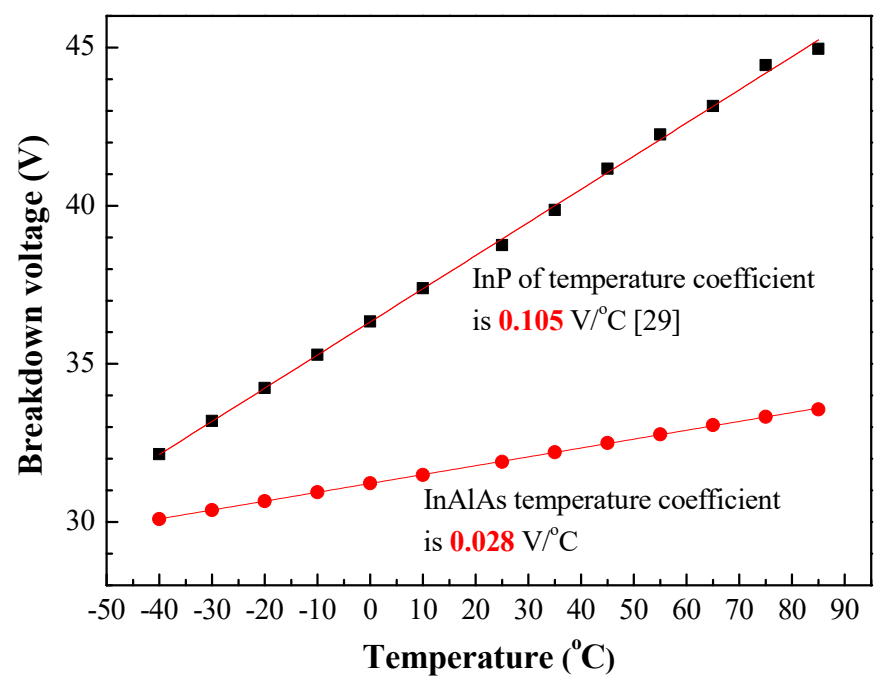

Figure 5. Breakdown voltage of InP-based [29] and InAlAs-based APD (current work) as a function of temperature. 
Figure 6 displays the photocurrent as a function of distance across the active area of the proposed mesa-structure SAGFM APD (diameter of $30 \mu \mathrm{m}$ ). Incident light was delivered using a distributed feedback (DFB) laser via a lens fiber at a wavelength of $1550 \mathrm{~nm}$ and a power of $1 \mu \mathrm{W}$. The light spot was moved in steps of $2 \mu \mathrm{m}$. None of the photocurrent curves presented a significant spike at the edge of the active region; however, the level of photocurrent produced within the active region was uniform, when the multiplication gain was varied between 1 and 10. This demonstrates the efficacy of the proposed mesa structure in suppressing edge-breakdown. It also demonstrates the high uniformity of the layer structure grown by MBE in terms of thickness and doping concentration in the field-control and multiplication layers.

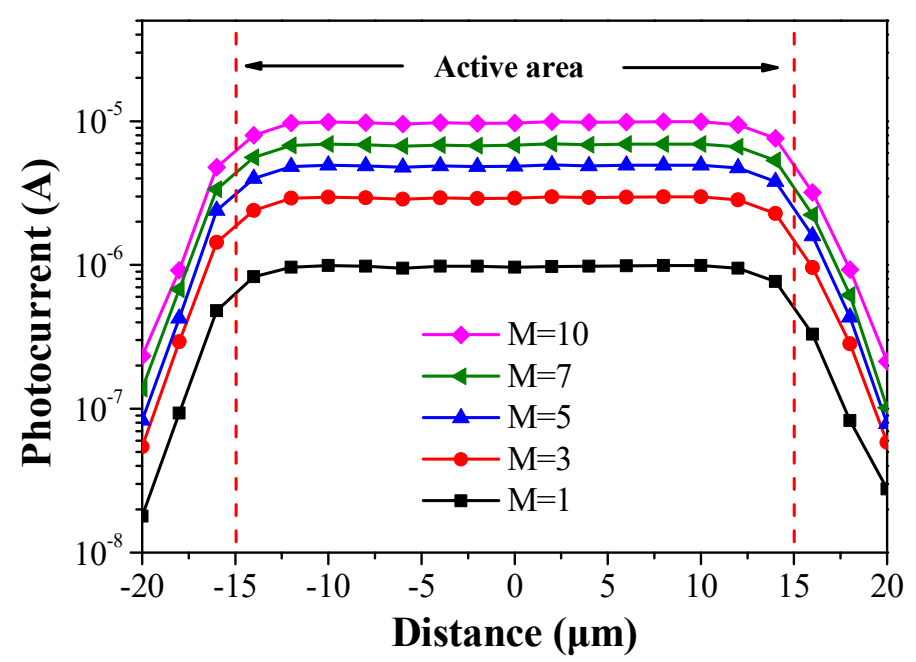

Figure 6. Photocurrent as a function of distance across the active area of the proposed SAGFM APD (i.e., diameter).

Figure 7 presents the measured photocurrent as a function of incident optical power and reverse bias voltage. Incident light was delivered using a DFB laser via a lens fiber at a wavelength of $1550 \mathrm{~nm}$. The black dashed lines in Figure 7 refer to APD devices operating with constant responsivity (R) across the full range of incident optical power. Here, the responsivity of $1.82 \mathrm{~A} / \mathrm{W}$ and $8.23 \mathrm{~A} / \mathrm{W}$ respectively refer to InGaAs/InAlAs SAGFM APDs operated at $20 \mathrm{~V}$ and $0.9 \mathrm{~V}_{\mathrm{BR}}$ linearly across the entire range of incident optical power. Ideally, the photocurrent values should closely match the dashed line, which would indicate that the incident optical power received by the APD covered a wide dynamic range (DR). In this study, the dynamic range of the APD device biased at $20 \mathrm{~V}(45.0 \mathrm{~dB})$ was larger than that of the device biased at $0.9 \mathrm{~V}_{\mathrm{BR}}(39.08 \mathrm{~dB})$. Under high incident optical power and high voltage biasing, the multiplication factor and photocurrent generated by the APD device were both high. The internal series resistance and external load resistance associated with high output photocurrent resulted in voltage potential on the two output terminals of APD device. This voltage potential would induce an increase in the internal shunt current with the result that the output photocurrent would be saturated by the incident optical power. In contrast, under low incident optical power, the measured output photocurrent would be limited by dark current. For the sake of clarity, we calculated the dynamic range (DR) values as follows: 


$$
D R(\mathrm{~dB})=10 \log \frac{P_{H}}{P_{L}} .
$$

where $P_{H}$ is the highest incident optical power (i.e., when output photocurrent is beginning to be saturated), $P_{L}$ is the lowest incident optical power (i.e., when the output photocurrent is equal to the dark current). Table 3 lists the calculated dynamic range of incident optical power.

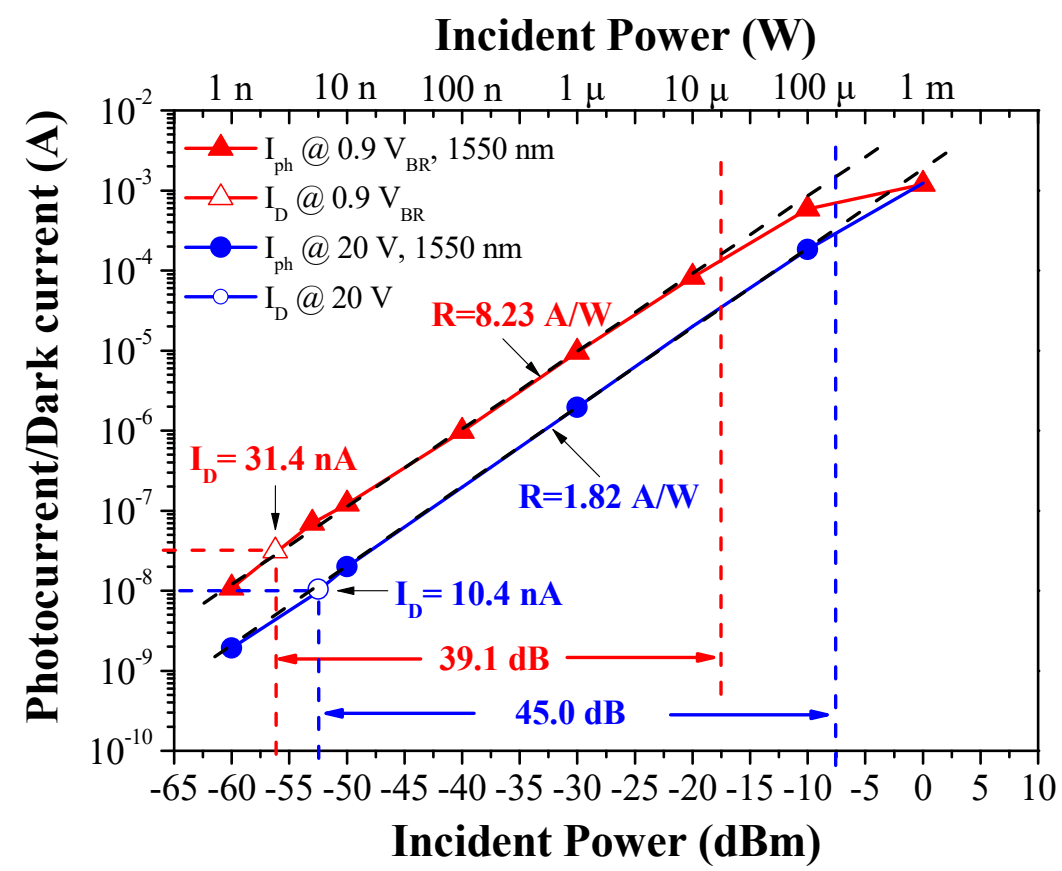

Figure 7. Measured photocurrent as a function of incident optical power and reverse bias voltage.

Table 3. Dynamic range of incident optical power.

\begin{tabular}{cccc}
\hline & DR (dB) & $\mathbf{P}_{\mathbf{H}}(\mathbf{W})$ & $\mathbf{P}_{\mathbf{L}}(\mathbf{W})$ \\
\hline$@ 0.9 \mathrm{~V}_{\mathrm{BR}}$ & 39.08 & $1.78 \times 10^{-5}$ & $2.2 \times 10^{-9}$ \\
$@ 20 \mathrm{~V}$ & 45.02 & $1.78 \times 10^{-4}$ & $5.6 \times 10^{-9}$ \\
\hline
\end{tabular}

Figure 8 presents the reverse dark current of four SAGFM APDs as a function of aging time. Current leakage and reliability are important issues when dealing with mesa-structure APD devices. Before conducting aging tests, we first screened test samples to obtain reference data for comparisons. The aging conditions included stress reverse current of $100 \mu \mathrm{A}$ and stress temperature of $85^{\circ} \mathrm{C}$ in an air atmosphere. As shown in Table 4, testing began after approximately 100-200 $\mathrm{h}$. The samples were measured at room temperature to monitor the dark current at $-25 \mathrm{~V}$ and then returned to the aging system to repeat the procedure. We did not detect a significant variation in dark current after aging for $1344 \mathrm{~h}$ (i.e., $15-20 \mathrm{nA}$ with S.D. $<1.6 \mathrm{nA}$, which is nearly identical to the values obtained in the screening stage). These results clearly demonstrate the efficacy of the proposed sulfur/polyimide passivation scheme for the treatment of SAGFM APD with a mesa-structure. 


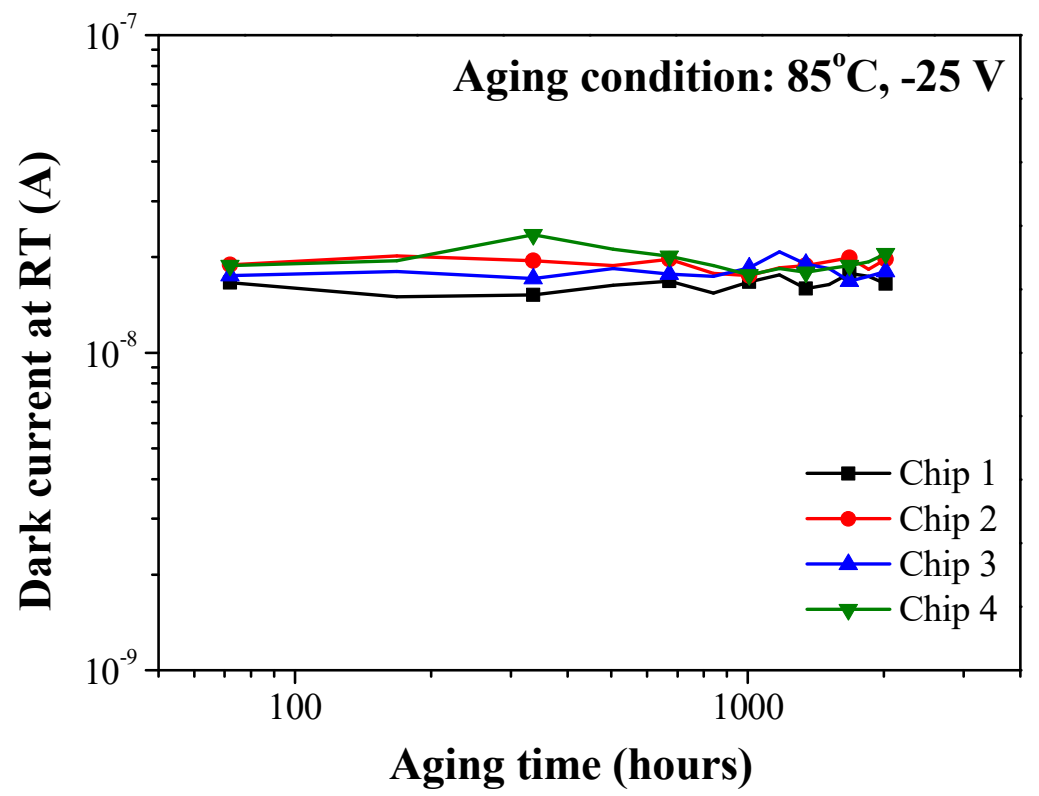

Figure 8. Variations in dark current measured at RT after aging. Aging conditions included reverse dark current of $100 \mu \mathrm{A}$ at $85^{\circ} \mathrm{C}$ in air atmosphere.

Table 4. Variations in the dark current of SAGFM APDs after stressed aging.

\begin{tabular}{|c|c|c|c|c|}
\hline Aging Time (hours) & Chip $1 I_{D}(n A)$ & Chip $2 I_{D}(n A)$ & Chip $3 I_{D}(n A)$ & Chip $4 I_{D}(n A)$ \\
\hline 0 & 15.5 & 17.9 & 16.8 & 17.6 \\
\hline 72 & 16.6 & 18.9 & 17.5 & 18.8 \\
\hline 168 & 15.0 & 20.2 & 18.0 & 19.5 \\
\hline 336 & 15.2 & 19.5 & 17.1 & 23.5 \\
\hline 504 & 16.3 & 18.8 & 18.4 & 21.2 \\
\hline 672 & 16.8 & 19.7 & 17.7 & 20.1 \\
\hline 840 & 15.4 & 17.8 & 17.4 & 18.8 \\
\hline 1008 & 16.7 & 17.5 & 18.5 & 17.6 \\
\hline 1176 & 17.6 & 18.5 & 20.8 & 18.4 \\
\hline 1344 & 15.9 & 18.8 & 19.0 & 17.9 \\
\hline 1512 & 16.4 & 19.4 & 18.4 & 18.4 \\
\hline 1680 & 17.8 & 19.9 & 16.8 & 18.8 \\
\hline 1848 & 17.4 & 18.3 & 17.4 & 19.3 \\
\hline 2016 & 16.5 & 19.7 & 18.0 & 20.5 \\
\hline Standard Deviation (S.D.; nA) & 0.8 & 0.8 & 1.0 & 1.6 \\
\hline
\end{tabular}

\subsection{AC Characteristics of SAGFM APD}

Figure 9 a presents the measured frequency response $\left(f_{3-\mathrm{dB}}\right)$ of the SAGFM APD under incident optical power of $1.0 \mu \mathrm{W}$ and reverse bias voltage of $0.9 \mathrm{~V}_{\mathrm{BR}}$, as measured under load resistance of $50 \Omega$ using a HP 8703A lightwave component analyzer. We measured $f_{3-\mathrm{dB}}$ of $8.97 \mathrm{GHz}$ at the chip level, which corresponds to an operating bit rate of $>10 \mathrm{Gbps}$. Figure $9 \mathrm{~b}$ presents $f_{3 \text {-dB }}$ as a function of multiplication gain from 2 to 50 . The highest $f_{3-\mathrm{dB}}$ bandwidth (approximately $9 \mathrm{GHz}$ ) was obtained within a multiplication gain range of $5-10$. The $f_{3-\mathrm{dB}}$ bandwidth increased with multiplication gain between 2 and 4, due to a reduction in capacitance associated with an increase in the depletion width of the APD under reverse bias voltage. The $f_{3-\mathrm{dB}}$ bandwidth also decreased when multiplication gain exceeded 10, due to an increase in avalanche build-up time with an increase in multiplication gain. The avalanche build-up time constant increased linearly with the multiplication gain and is also proportional to the ionization coefficient ratio ( $k$ ) [30]. In general, the gain-bandwidth (GB) product of APD is inversely proportional to the mean drift time of carriers within the avalanche region and is proportional to the ionization coefficient ratio [31]. Therefore, the k-ratio should be as small as 
possible to improve the GB-product. Overall, the gain-bandwidth product of the proposed SAGFM APD reached $88 \mathrm{GHz}$.
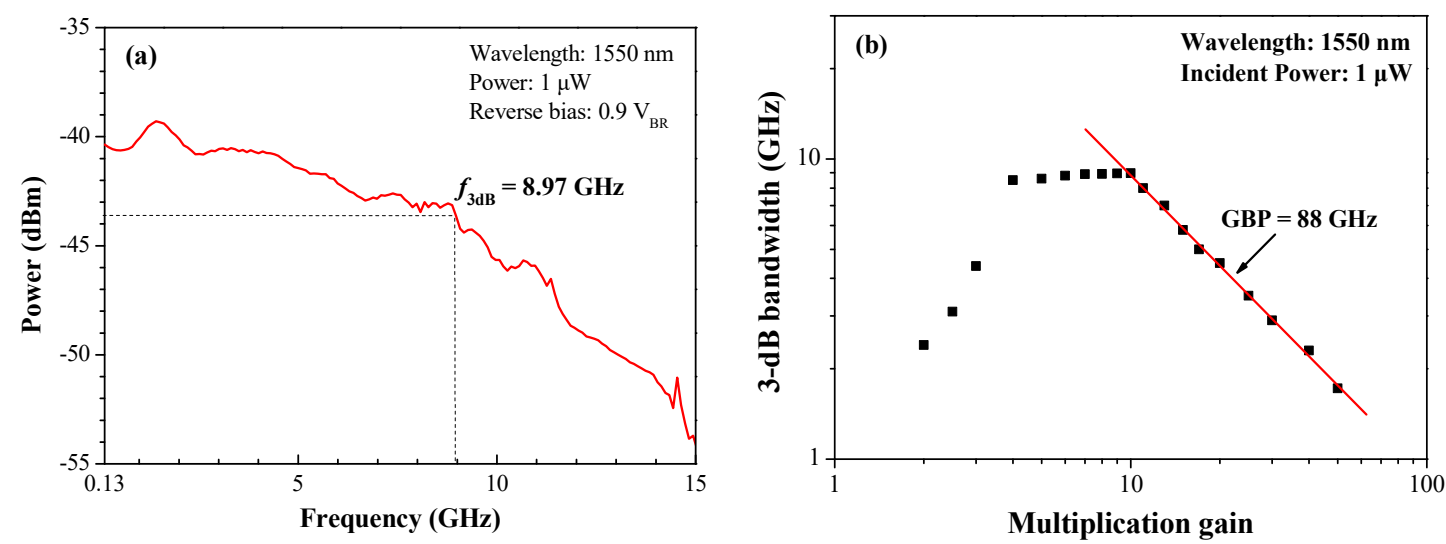

Figure 9. (a) Measured frequency response of SAGFM APD under incident optical power of $1.0 \mu \mathrm{W}$ and reverse bias voltage of $0.9 \mathrm{~V}_{\mathrm{BR}} ;(\mathbf{b})$ Measured $f_{3-\mathrm{dB}}$ bandwidth as a function of multiplication factor from 2 to 50.

Figure 10 presents eye diagrams of the InGaAs/InAlAs SAGFM APD, under a fixed multiplication gain of 10 using nonreturn-to-zero (NRZ) pseudorandom codes with a length of $2^{31}-1$, under operating speeds corresponding to bit rates of (a) 10, (b) 11 , (c) 12 and (d) $12.5 \mathrm{~Gb} / \mathrm{s}$. A rise time of approximately 38.9-42.0 ps was derived from the eye-diagrams. Observe that we detected a notable absence of intersymbol-interference and the signals remained error-free at data-rates of up to $12.5 \mathrm{Gbps}$. Figure 11 presents the eye diagrams obtained from the InGaAs/InAlAs SAGFM APD operated under multiplication gains of (a) 3, (b) 5, (c) 10, (d) 20, (e) 30 with the bit rate fixed at $10 \mathrm{~Gb} / \mathrm{s}$. A $10 \mathrm{~Gb} / \mathrm{s}$ built-in eye mask was used to evaluate the APD operated with a suitable multiplication gain; i.e., where the transmitted signals would be not present within the eye mask region. We determined that multiplication gains of 5 and 10 were the optimal choices. We sought to characterize the dynamic range of the AC optical power by obtaining eye diagrams of InGaAs/InAlAs SAGFM APD operated at $10 \mathrm{~Gb} / \mathrm{s}$ with various incident optical powers $(-17.22 \mathrm{dBm},-12.22 \mathrm{dBm},-7.22 \mathrm{dBm},-0.22 \mathrm{dBm}$ and $0.78 \mathrm{dBm}$ ) at room temperature, as shown in Figure 12. Similarly, the transmitted signals should not be present within the eye mask region. This was achieved when the dynamic range of incident optical power ranged from $-12.22 \mathrm{dBm}$ to $0.78 \mathrm{dBm}$. Thus, the dynamic range of $\mathrm{AC}$ incident optical power was approximately $13 \mathrm{~dB}$, which is less than that of $\mathrm{DC}$ incident optical power $(45 \mathrm{~dB})$. Table 5 lists time response and calculation of $f_{3 \text {-dB }}$ data using values obtained from eye diagram measurements.
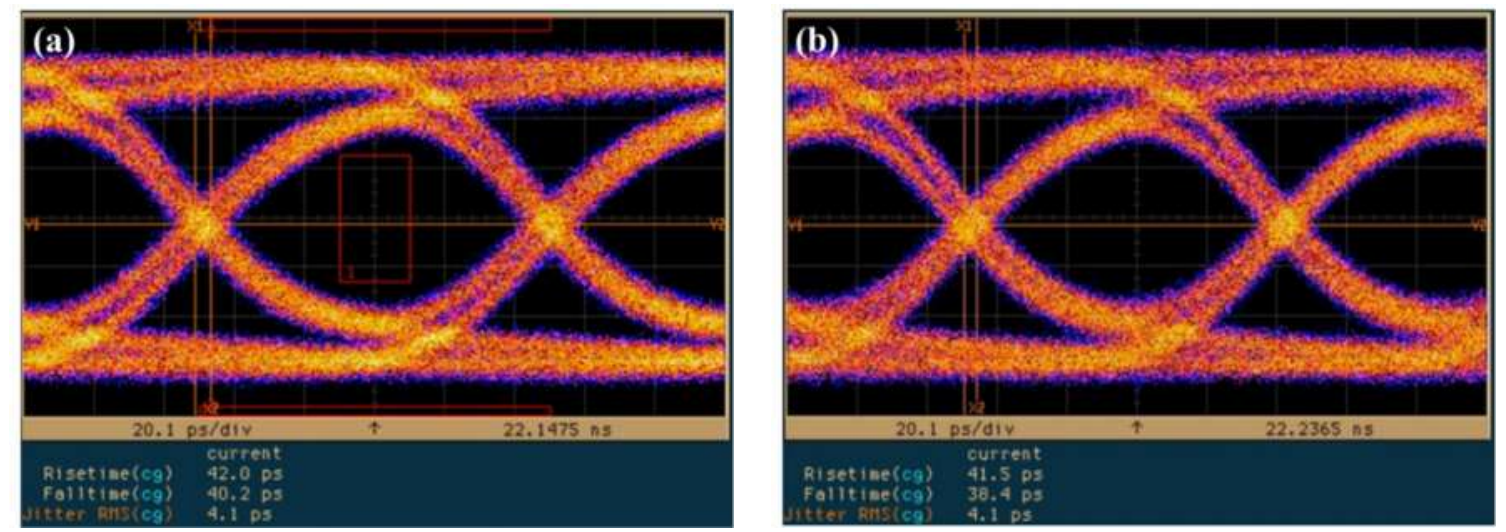

Figure 10. Cont. 

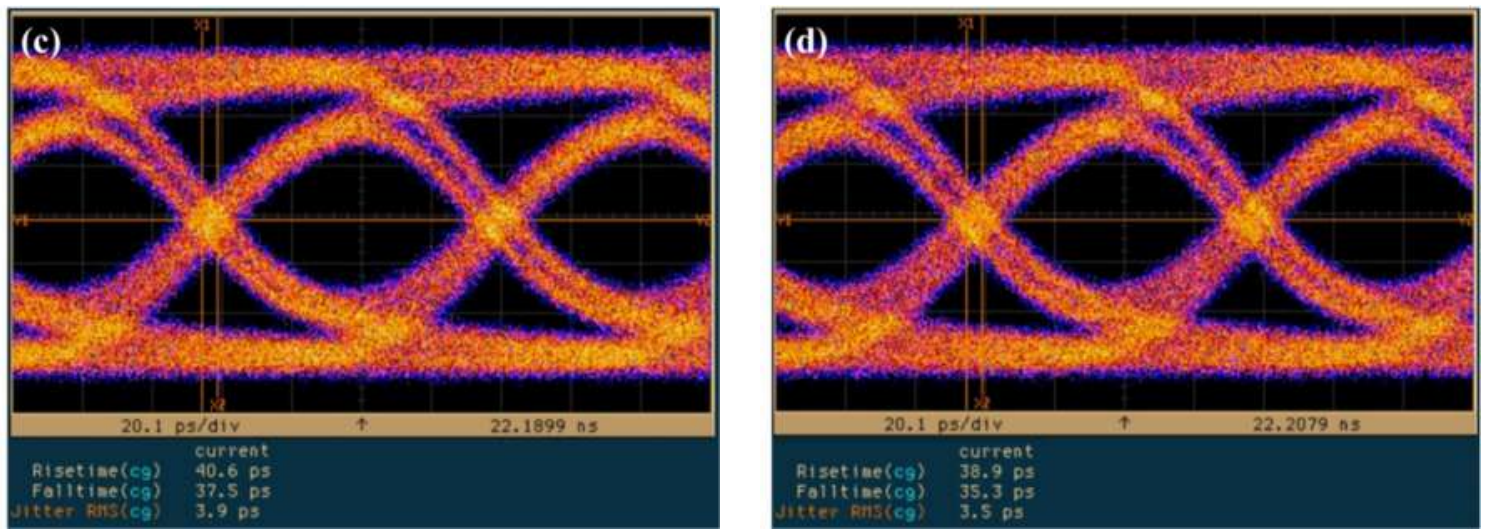

Figure 10. Eye diagrams of SAGFM-APD operated under a multiplication gain of 10 and at bit rates of (a) 10 , (b) 11 , (c) 12 and (d) $12.5 \mathrm{~Gb} / \mathrm{s}$.
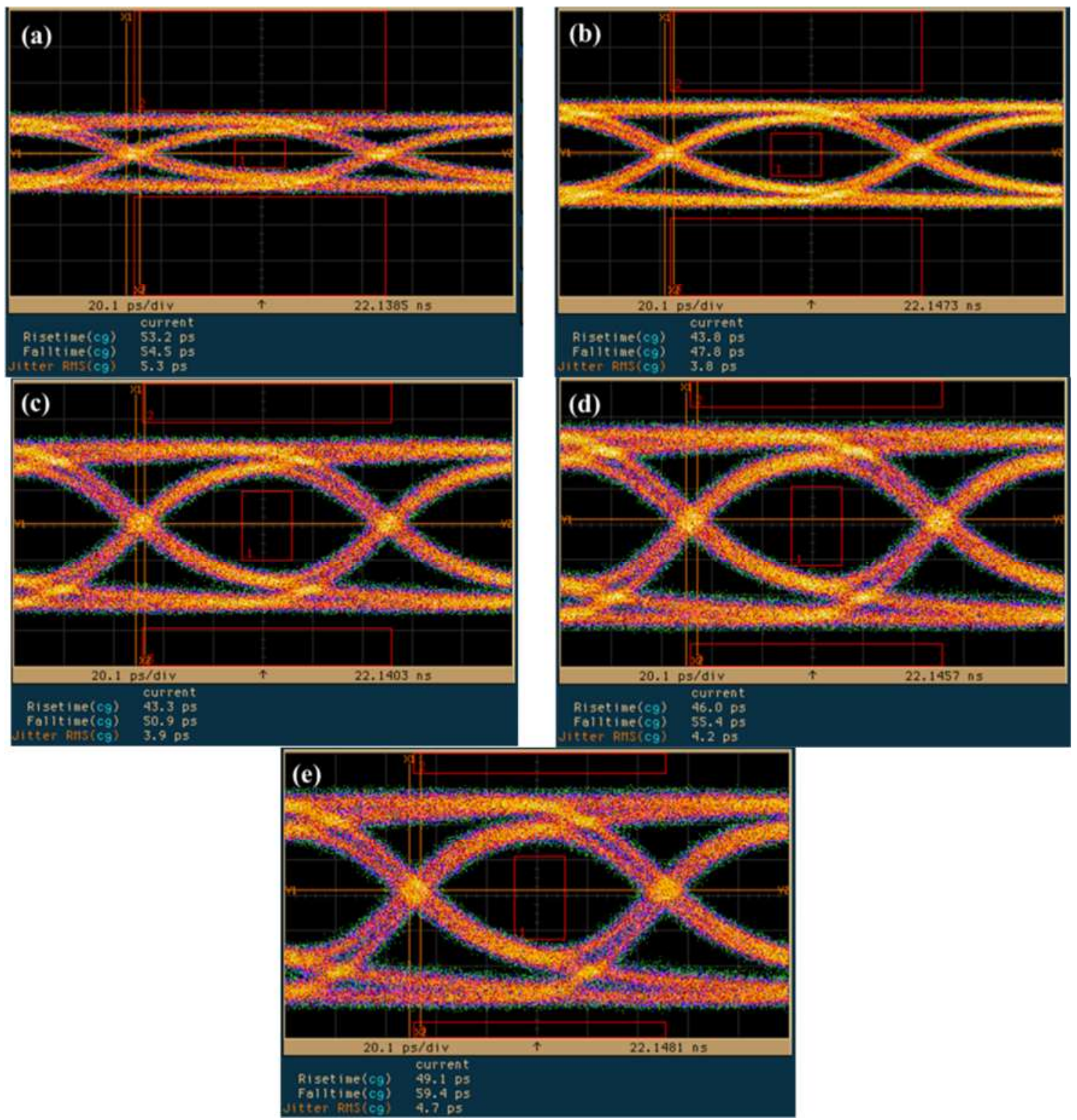

Figure 11. Eye diagrams of SAGFM-APD operated under multiplication gains of (a) 3, (b) 5, (c) 10, (d) 20, (e) 30 at a bit rate of $10 \mathrm{~Gb} / \mathrm{s}$. 

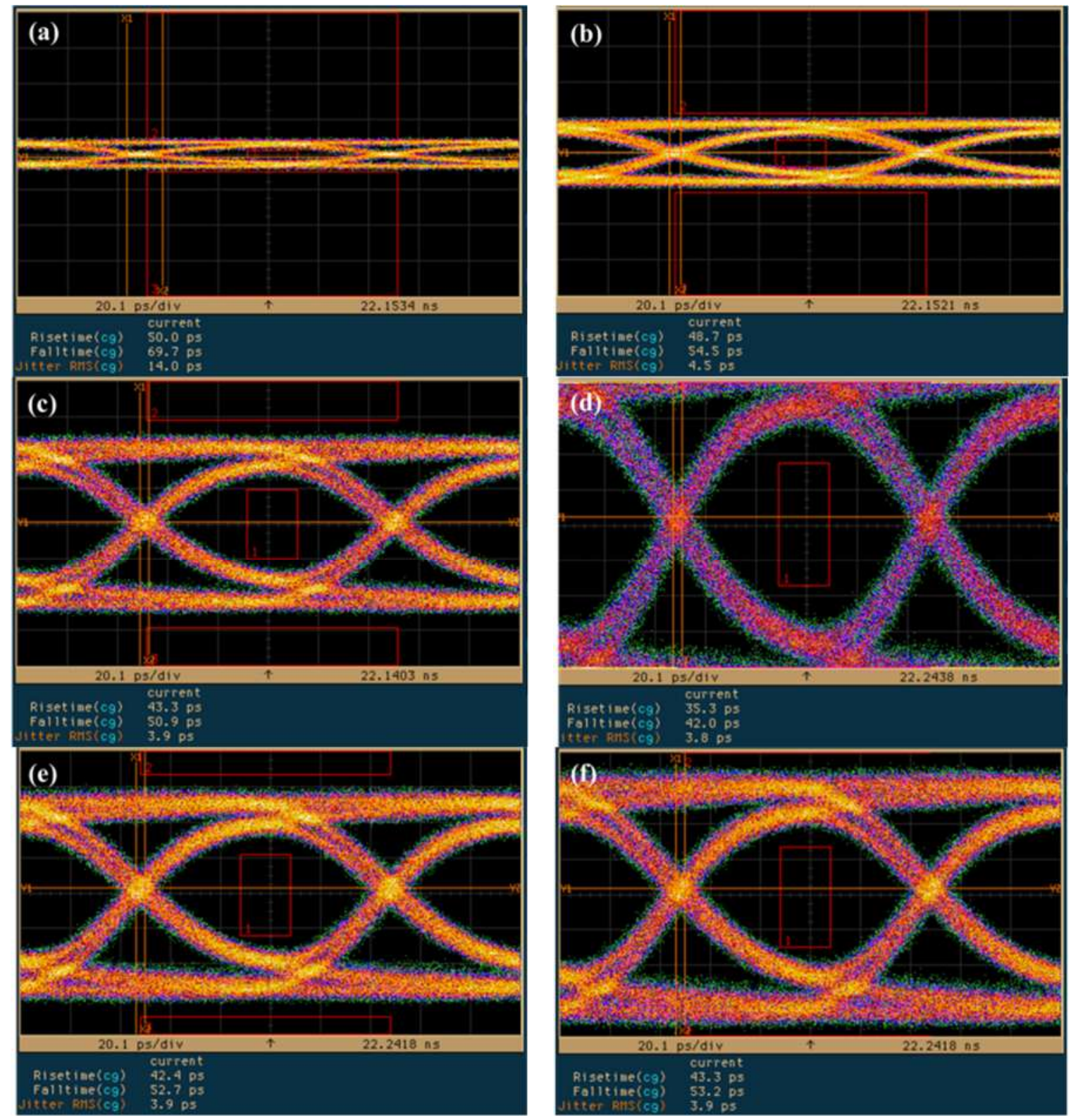

Figure 12. Eye diagrams of SAGFM-APD operated under incident powers of (a) $-17.22 \mathrm{dBm}$, (b) $-12.22 \mathrm{dBm},(\mathbf{c})-7.22 \mathrm{dBm},(\mathbf{d})-0.22 \mathrm{dBm},(\mathbf{e}) 0.78 \mathrm{dBm}$ at a bit rate of $10 \mathrm{~Gb} / \mathrm{s}$ with a multiplication gain of 10. Note: (a-d) The vertical scale is $15 \mathrm{mV} ;(\mathbf{e}, \mathbf{f})$ the vertical scale is $40 \mathrm{mV}$.

Table 5. Time response and calculation of $f_{3-\mathrm{dB}}$ data using values obtained from eye diagram measurements.

\begin{tabular}{ccc}
\hline Speeds $@ \mathbf{M}=\mathbf{1 0}$ & Rise Time $\mathbf{( p s )}$ & Calculate $\boldsymbol{f}_{\mathbf{3 - d B}} \mathbf{( G H z )}$ \\
\hline Bit rate: $10 \mathrm{~Gb} / \mathrm{s}$ & 42.0 & 8.33 \\
Bit rate: $11 \mathrm{~Gb} / \mathrm{s}$ & 41.5 & 8.43 \\
Bit rate: $12 \mathrm{~Gb} / \mathrm{s}$ & 40.6 & 8.62 \\
Bit rate: $12.5 \mathrm{~Gb} / \mathrm{s}$ & 38.9 & 8.99 \\
\hline Multiplication Gain $@ 10 \mathrm{~Gb} / \mathrm{s}$ & - & - \\
\hline $\mathrm{M}=3$ & 53.2 & 6.58 \\
$\mathrm{M}=5$ & 43.8 & 7.99 \\
$\mathrm{M}=10$ & 43.3 & 8.08 \\
$\mathrm{M}=20$ & 46.0 & 7.61 \\
$\mathrm{M}=30$ & 49.1 & 7.13 \\
\hline
\end{tabular}


Table 5. Cont.

\begin{tabular}{ccc}
\hline Speeds $@ \mathbf{M}=\mathbf{1 0}$ & Rise Time (ps) & Calculate $f_{3-\mathbf{d B}}(\mathbf{G H z})$ \\
\hline Incident power $(\mathrm{dBm}) @ 10 \mathrm{~Gb} / \mathrm{s}, \mathrm{M}=10$ & - & - \\
\hline-17.22 & 50.0 & 7.00 \\
-12.22 & 48.7 & 7.19 \\
-7.22 & 43.3 & 8.08 \\
-2.22 & 35.3 & 9.91 \\
-0.22 & 42.4 & 8.25 \\
0.78 & 43.3 & 8.08 \\
\hline
\end{tabular}

\section{Conclusions}

This paper presents the fabrication and characterization of InAlAs/InGaAs SAGFM APDs with a mesa-structure to enable high-speed operations. The side walls of the mesa underwent sulfur treatment before being coated with a thick polyimide passivation layer, to reduce current leakage, reduce capacitance, increase response speeds and enhance reliability. The passivation effects were shown to reduce surface recombination and current leakage, as indicated by a reduction in ideality factor and reverse saturation current. The breakdown temperature coefficient of InGaAs/InAlAs APD was approximately $0.028 \mathrm{~V} /{ }^{\circ} \mathrm{C}$, which indicates that the proposed device is highly insensitive to temperature variations. Under 0.9 breakdown voltage biasing, we obtained impressive results in terms of dark current $(31.4 \mathrm{nA})$, capacitance $(0.19 \mathrm{pF})$ and multiplication gain (10) at room temperature. The dynamic range of DC incident optical power was approximately $45 \mathrm{~dB}$, which is higher than that of AC incident optical power (13 dB). We observed only a negligible change in dark current (i.e., 15-20 nA) after aging for $1344 \mathrm{~h}$. We also obtained $f_{3-\mathrm{dB}}$ of $8.91 \mathrm{GHz}$ and gain-bandwidth product up to $88 \mathrm{GHz}$. In eye-diagrams, there was also a notable absence of intersymbol-interference and the signals remained error-free at data-rates of up to 12.5 Gbps.

Author Contributions: All of the authors conceived the experiments; W.-J.H. designed, analyzed and wrote the first draft of the paper; J.-J.L., J.-Y.C., J.-N.L., Y.-C.L. and M.-J.C. performed the experiments; C.-J.T. and C.-C.Y. conducted APD chip measurements; all authors contributed to the discussion.

Funding: The authors would like to thank the Tyntek Corporation for their financial support and the authors would like to thank the Ministry of Science and Technology of the Republic of China for their financial support under Grant MOST 106-2221-E-027-101-MY3.

Conflicts of Interest: The authors declare no conflict of interest.

\section{References}

1. Murtaza, S.; Anselm, K.; Hu, C.; Nie, H.; Streetman, B.; Campbell, J. Resonant-cavity enhanced (RCE) separate absorption and multiplication (SAM) avalanche photodetector (APD). IEEE Photonics Technol. Lett. 1995, 7, 1486-1488. [CrossRef]

2. Anselm, K.; Nie, H.; Hu, C.; Lenox, C.; Yuan, P.; Kinsey, G.; Campbell, J.; Streetman, B. Performance of thin separate absorption, charge, and multiplication avalanche photodiodes. IEEE J. Quantum Electron. 1998, 34, 482-490. [CrossRef]

3. Zhao, Y.; Zhang, D.; Qin, L.; Tang, Q.; Wu, R.H.; Liu, J.; Zhang, Y.; Zhang, H.; Yuan, X.; Liu, W. InGaAs-InP avalanche photodiodes with dark current limited by generation-recombination. Opt. Express 2011, 19, 8546-8556. [CrossRef] [PubMed]

4. Ribordy, G.; Gisin, N.; Guinnard, O.; Stucki, D.; Wegmuller, M.; Zbinden, H. Photon counting at telecom wavelengths with commercial InGaAs/InP avalanche photodiodes: current performance. J. Mod. Opt. 2004, 51, 1381-1398.

5. Lee, M.H.; Ha, C.; Jeong, H.-S.; Kim, D.W.; Lee, S.H.; Lee, M.H.; Kim, K.H. Wavelength-division-multiplexed InGaAs/InP avalanched photodiodes for quantum key distributions. Opt. Commun. 2016, 361, 162-167. [CrossRef] 
6. Yu, Y.-J.; Bosman, G.; Bhattacharya, P.K. Impact ionization coefficient ratio in InGaAs/InAlAs superlattice avalanche photodiodes determined from noise measurements. Appl. Phys. Lett. 1987, 51, 1433-1435. [CrossRef]

7. Goh, Y.L.; Massey, D.J.; Marshall, A.R.J.; Ng, J.S.; Tan, C.H.; Ng, W.K.; Rees, G.J.; Hopkinson, M.; David, J.P.R.; Jones, S.K. Avalanche Multiplication in InAlAs. IEEE Trans. Electron Devices 2007, 54, 11-16. [CrossRef]

8. Capasso, F.; Mohammed, K.; Alavi, K.; Cho, A.Y.; Foy, P.W. Impact ionization rates for electrons and holes in Al0.48In0.52As. Appl. Phys. Lett. 1984, 45, 968-970. [CrossRef]

9. Watanabe, I.; Torikai, T.; Makita, K.; Fukushima, K.; Uji, T. Impact ionization rates in (100) Al0.48In0.52As. IEEE Electron Device Lett. 1990, 11, 437-438. [CrossRef]

10. Takanashi, Y.; Muramoto, Y.; Takahata, K. Characteristics of InAlAs/InGaAs high-electron-mobility transistors under illumination with modulated light. IEEE Trans. Electron Devices 1999, 46, 2271-2277. [CrossRef]

11. Watanabe, T.; Boubanga-Tombet, S.A.; Tanimoto, Y.; Fateev, D.; Popov, V.; Coquillat, D.; Knap, W.; Meziani, Y.M.; Wang, Y.; Minamide, H.; et al. InP and GaAs-Based Plasmonic High-Electron-Mobility Transistors for Room-Temperature Ultrahigh-Sensitive Terahertz Sensing and Imaging. IEEE Sens. J. 2013, 13, 89-99. [CrossRef]

12. Osaka, F.; Mikawa, T. Low-temperature characteristics of electron ionization rates in (100)-and (111)-oriented InP. J. Appl. Phys. 1985, 58, 4426-4430. [CrossRef]

13. Taguchi, K.; Torikai, T.; Sugimoto, Y.; Makita, K.; Ishihara, H. Temperature dependence of impact ionization coefficients in InP. J. Appl. Phys. 1986, 59, 476-481. [CrossRef]

14. Goh, Y.L.; Marshall, A.R.J.; Massey, D.J.; Ng, J.S.; Tan, C.H.; Hopkinson, M.; David, J.P.R.; Jones, S.K.; Button, C.C.; Pinches, S.M. Excess avalanche noise in In0:52A10:48As. IEEE J. Quantum Electron. 2007, 43, 503-507. [CrossRef]

15. Yuan, Y.; Zheng, J.; Tan, Y.; Peng, Y.; Rockwell, A.-K.; Bank, S.R.; Ghosh, A.; Campbell, J.C. Temperature dependence of the ionization coefficients of InAlAs and AlGaAs digital alloys. Photonics Res. 2018, 6, 794-799. [CrossRef]

16. Campbell, J.C.; Demiguel, S.; Ma, F.; Beck, A.; Guo, X.; Wang, S.; Zheng, X.; Li, X.W.; Beck, J.D.; Kinch, M.A.; et al. Recent Advances in Avalanche Photodiodes. J. Light. Technol. 2016, 34, 777-787. [CrossRef]

17. Kleinow, P.; Rütz, F.; Aidam, R.; Bronner, W.; Heussen, H.; Walther, M. Experimental investigation of the charge-layer doping level in InGaAs/InAlAs avalanche photodiodes. Infrared Phys. Technol. 2015, 71, $298-302$. [CrossRef]

18. Ma, Y.; Zhang, Y.; Gu, Y.; Chen, X.; Shi, Y.; Ji, W.; Xi, S.; Du, B.; Li, X.; Tang, H.; et al. Impact of etching on the surface leakage generation in mesa-type InGaAs/InAlAs avalanche photodetectors. Opt. Express 2016, 24, 7823. [CrossRef]

19. Huang, J.J.-S.; Chang, H.S.; Jan, Y.-H.; Ni, C.J.; Chen, H.S.; Chou, E. Temperature Dependence Study of Mesa-Type InGaAs/InAlAs Avalanche Photodiode Characteristics. Adv. Optoelectron. 2017, 2017, 1-5. [CrossRef]

20. Kim, H.; Choi, J.; Bang, H.; Jee, Y.; Yun, S.; Burm, J.; Kim, M.; Choo, A. Dark current reduction in APD with BCB passivation. Electron. Lett. 2001, 37, 455-457. [CrossRef]

21. Watanabe, I.; Tsuji, M.; Hayashi, M.; Makita, K.; Taguchi, K. Design and performance of InAlGaAs/InAlAs superlattice avalanche photodiodes. J. Light. Technol. 1997, 15, 1012-1019. [CrossRef]

22. Suzuki, A.; Yamada, A.; Yokotsuka, T.; Idota, K.; Ohki, Y. Dark Current Reduction of Avalanche Photodiode Using Optimized InGaAsP/InAlAs Superlattice Structure. Jpn. J. Appl. Phys. 2002, 41, 1182-1185. [CrossRef]

23. Stareev, G.; Kü̈nzel, H. Tunneling behavior of extremely low resistance nonalloyed Ti/Pt/Au contacts to n(p)-InGaAs and n-InAs/InGaAs. J. Appl. Phys. 1993, 74, 7592-7595. [CrossRef]

24. Kim, J.; Kim, K.M.; Jeon, S.K.; Kim, M.; Park, E.H.; Kwon, Y.S. Successively Dry-Wet Etched InP Microlens for Bell Shaped LED. In Proceedings of the International Conference on Indium Phosphide and Related Materials, Santa Barbara, CA, USA, 12-16 May 2003.

25. Brennan, B.; Milojevic, M.; Hinkle, C.; Aguirre-Tostado, F.; Hughes, G.; Wallace, R.; Wallace, R. Optimisation of the ammonium sulphide (NH4)2S passivation process on In0.53Ga0.47As. Appl. Surf. Sci. 2011, 257, 4082-4090. [CrossRef] 
26. Lai, L.W.; Chen, J.T.; Lou, L.R.; Wu, C.H.; Lee, C.T. Performance Improvement of $\left(\mathrm{NH}_{4}\right)_{2} \mathrm{~S}_{\mathrm{x}}$-Treated III-V Compounds Multijunction Solar Cell Using Surface Treatment. J. Electrochem. Soc. 2008, 155, B1270. [CrossRef]

27. Sheela, D.; Dasgupta, N. Optimization of surface passivation for InGaAs/InP pin photodetectors using ammonium sulfide. Semicond. Sci. Technol. 2008, 23, 35018. [CrossRef]

28. Fu, M.C.; Higashihara, T.; Ueda, M. Recent progress in thermally stable and photosensitive polymers. Polym. J. 2018, 50, 57-76. [CrossRef]

29. Liu, J.J.; Ho, W.J.; Chiang, C.C.; Teng, C.J.; Yu, C.C.; Li, Y.C. Fabrication and Characterization of Planar-Type Top-Illuminated InP-Based Avalanche Photodetector on Conductive Substrate with Operating Speeds Exceeding 10 Gbps. Sensors 2018, 18, 2800. [CrossRef]

30. Campbell, J.C.; Tsang, W.T.; Qua, G.J.; Bowers, J.E. InP/InGaAsP/InGaAs avalanche photodiodes with $70 \mathrm{GHz}$ gain-bandwidth product. Appl. Phys. Lett. 1987, 51, 1454-1456. [CrossRef]

31. Emmons, R.B. Avalanche-Photodiode Frequency Response. J. Appl. Phys. 1967, 38, 3705. [CrossRef]

(C) 2019 by the authors. Licensee MDPI, Basel, Switzerland. This article is an open access article distributed under the terms and conditions of the Creative Commons Attribution (CC BY) license (http://creativecommons.org/licenses/by/4.0/). 